\title{
Drug Use, a Valid Indicator of Effective Implementation of Medical Protocols
}

\author{
MONICA MARILENA TANTU1 ${ }^{1}$, GEORGE MIHAIL MAN ${ }^{1}$, LILIANA ROGOZEA², ALINA PAUNESCU1*, CRISTINA FLORENTINA PLESA ${ }^{3}$, \\ ROXANA MARIA NEMES ${ }^{3}$, CAMELIA NICOLAE ${ }^{4}$, ALINA BISOC ${ }^{2}$ \\ ${ }^{1}$ University of Pitesti, Faculty of Sciences, Physical Education and Informatics, Medical Assistance and Physical Therapy \\ Department, 1 Targu din Vale Str., 110040, Pitesti, Romania \\ ${ }^{2}$ Transilvania University of Brasov, Faculty of Medicine, 29 Eroilor 29 Blvd., 500036, Brasov, Romania \\ ${ }^{3}$ Titu Maiorescu University of Bucharest, Faculty of Medicine, 22 Dambovnicului, 040441, Bucharest, Romania \\ ${ }^{4}$ Carol Davila University of Medicine and Pharmacy, 8 Eroii Sanitari Blvd., 050474, Bucharest, Romania
}

The effectiveness of pharmacological therapies is supported and guaranteed by medical protocols, which are the result of long-lasting experiments and scientific research, of course adapted to the level of competence and functional capacity of the healthcare provider. Besides pharmacological effectiveness, the therapeutic regimens should be evaluated from the point of view of economic efficiency, by assessing the financial impact of drug consumption, in correlation with other indicators specific to medical management $A$ retrospective comparative study of drug used in a surgical section with a capacity of 25 beds, from a county hospital is described. Study objective was to identify the relationship of influence and determination between costs with drugs and other economic and financial indicators and the use of services; objectively evaluate the effectiveness of the protocols used to limit the development of antibiotic resistance, avoiding polypharmacyand improving costs related to drug use, butespecially to determine the existence of deviations from these and generating causes. The implementation of medical protocols has led to a decrease in drug costs. Tracking drug use is an effective tool to increase the quality of medical services by avoiding polypharmacy, therapeutic errors and preventing the development of antibiotic resistance. All these aspects are supported by the implementation of medical protocols and, thus, drug use can be appreciated as a valid indicator of their effectiveness and efficiency.

Key words: medical protocols, medication costs, quality

An important contributor to improving the quality of medical services, optimizing drug therapy is an important desideratum for every practitioner. The optimal therapeutic regimen has to fulfill two essential, effective and efficient conditions, being placed at their convergence. The priority is to prove effective for the patient, taking into account their pathology, biological status, potential complications, prognosis and specific evolution. Hence, the major objective is that of rehabilitating health as soon as possible, with no invalidating consequences or, if these can not be avoided, it should be reduced, so that the quality of life of the patient should not be significantly affected.

The effectiveness of pharmacological therapies is supported and guaranteed by medical protocols, which are the result of long-term practical experiments and scientific research, of course adapted to the level of competence and functional capacity of the healthcare provider. The use of medical protocols has as a consequence the unitary approach of the case, reducing/ eliminating the variability of professional practice, ensuring the quality and continuity of care, in safe circumstances for the patient.

In addition to pharmacological efficacy, therapeutic regimens should also be evaluated from the point of view of economic efficiency by assessing the financial impact of drug use in correlation with other indicators specific to medical management.

\section{Experimental part}

\section{Material and method}

Based on these considerations, in order to highlight the benefits of implementing medical protocols and their integration into the clinical and financial managerial process, we conducted a retrospective comparative study on drug use in a surgical section with a capacity of 25 beds in a county hospital. The objective of this study was to identify the relationships of influence and determination between the drugs costs and other economic-financial indicators and the use of the services. At the same time, the analytical approach was intended to be an objective evaluation of the effectiveness of the protocols used to limit the development of antibiotic resistance, to avoid polypharmacy and to improve the costs related to drug use, but especially to establish deviations from them and generating causes.

The analysis took into account the consumption of drugs in the first trimester of 2017 and 2018 respectively. It has been chosen for these intervals so that reporting should be done to similar conditions in terms of addressability, the type of pathology treated. In addition, in the first quarter of 2018 , it is required a 12-month assessment of the process of implementing medical protocols on specific pathologies, but especially those for antibiotic prophylaxis and judicious use of antibiotics. The necessary data were collected from the general observation sheets, the register of medical prescriptions and the information management system of the medical activity. Data processing complies with ethical rules [1] and legal provisions on personal data [2].

\section{Results and discussions}

The analytical approach started from the identification of drug costs for each evaluated period and there was a decrease of $35.78 \%$ in the first quarter of 2018 compared to the same period of 2017 (the decrease is statistically significant, $p=0$ ) (fig. 1). 


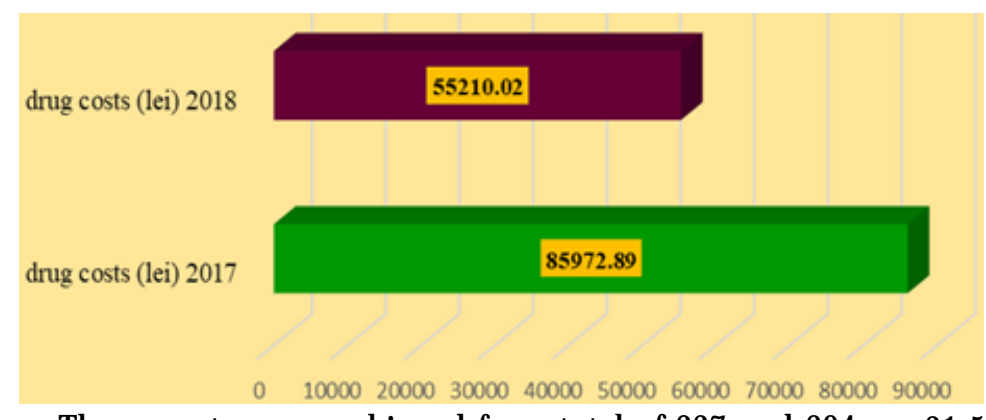

Fig. 1. Drug costs over the analyzed periods

These costs were achieved for a total of 237 and 204 patients, respectively. As it can be seen in figure 2, average costs per patient as well are lower in 2018 compared to 2017 by $25.39 \%$ ( $p=0.00000000151963)$, as the total number of patients is lower. This result, together with the previous one, supports the utility of using protocols as an important part of an effective cost-cutting policy.

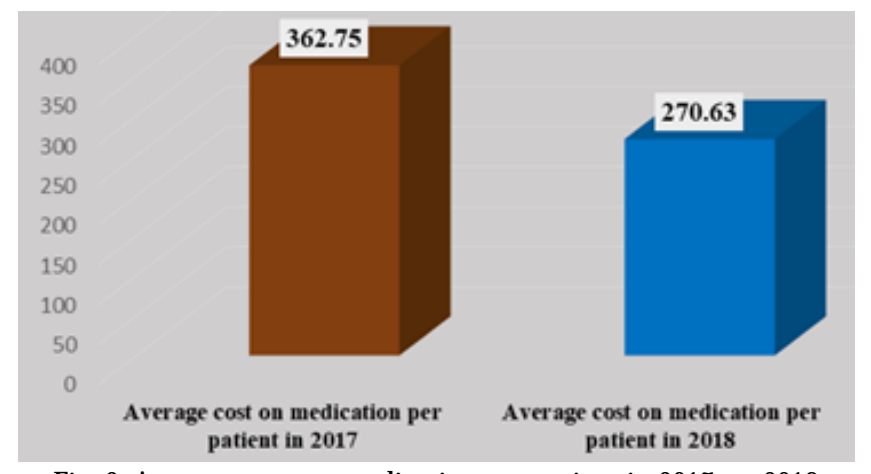

Fig. 2. Average cost on medication per patient in 2017 vs. 2018 The situation is similar in the case of hospitalization days for the analyzed intervals, which are lower for 2018 with
$31.53 \%$ (the average cost per day of hospitalization is significantly lower in 2018 vs 2017, $p=0.000000055653$ ) (fig. 3).

Drug costs represent an important component of the department's income and expenses budget, with a significant weight in the direct costs category, usually in a higher position than the costs with the sanitary materials used in care of the sick. It should be taken into account that the surgical specificity of the study department is oriented towards a higher importance of local treatment in the management of each case, which leads to substantial costs as well as for sanitary materials. Moreover, local treatment protocols recommend the use of new practices made with medical products that are not cheap. This is highlighted for the quarters analyzed in the next chart, where one can see a reversal of the drug costs / sanitary material costs for 2018, most likely influenced by the predominance of a particular pathology, characterized by high costs for local treatment (such as burns, diabetic foot etc.), but also by applying up to date techniques in wound care, indicated by guides and protocols, with proven therapeutic effectiveness, but with higher material costs (fig. 4).

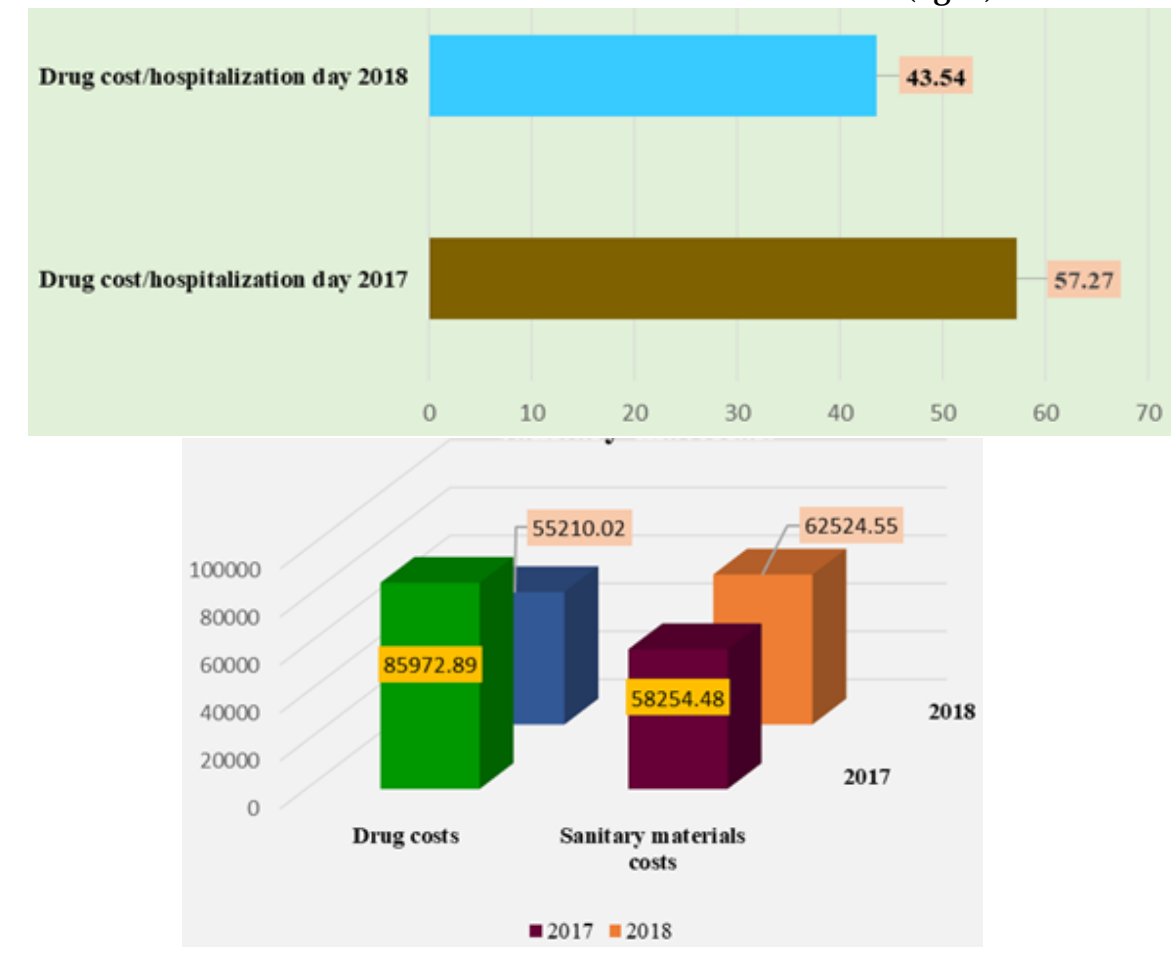

Fig. 3. Average cost on medication per hospitalization day

Fig. 4. Comparative situation of costs on drugs and sanitary materials

\begin{tabular}{|c|c|c|c|c|}
\hline Crt. & Pathology & $\begin{array}{l}\text { Number of cases per } \\
\text { 1st trimester } 2017\end{array}$ & $\begin{array}{l}\text { Number of cases per } \\
1 \text { st trimester } 2018\end{array}$ & Table 1 \\
\hline 1. & Burns up to $30 \%$ of the body surface & 34 & 29 & COMPARATIVF \\
\hline 2. & Hand trauma & 36 & 42 & SITUATION OF THF \\
\hline 3. & Foot trauma & 8 & 23 & SIIUAIIUIV UT IHE \\
\hline 4. & Cellulite with various locations & 52 & 24 & SURGICAL PATHOLOGY \\
\hline 5. & Osteitis & 16 & 16 & TREATED DURING THE \\
\hline 6. & Epitheliomas of the skin & 23 & 39 & \\
\hline 7. & $\begin{array}{l}\text { Benign tumors of the skin and connective tissue } \\
\text { with various localizations }\end{array}$ & 83 & 109 & \\
\hline 8. & Carpal channel syndrome & 6 & 3 & \\
\hline
\end{tabular}


In 2018, drug costs are significantly lower than in 2017 $(p=0)$. In contrast, the costs with sanitary materials are significantly higher $(p=0)$ than in 2017. In 2017, drug costs are significantly higher than in sanitary ware $(p=0)$, and in 2018 the situation changes $(p=0)$. Drug use is directly influenced by the type of treated pathology, also taking into account the various comorbidities present in the studied patients (table 1).

It should be noted that for both periods there were cases that presented two categories of disorders, such as, for example, hand or foot trauma with cellulite, which are considered statistically according to each diagnostic code. It is evident the prevalence of benign tumors of skin and connective tissue and cutaneous epitheliomas, followed by hand trauma and burns with different localizations. The results obtained with the prevalence of skin tumors are supported by the findings of another study conducted in 2012 in the same service [3].

The most common comorbidities found were type I or 11 diabetes $(52$ cases vs 44 cases - $\mathrm{p}=$ 0.000173309675567279 ), hypertension (79 patients vs 77 patients $p=0.19812670736882$ ), atrial fibrillation ( 10 cases vs 14 cases $p=0.0036819135060151$ ), embolism and arterial thrombosis ( 6 cases vs 12 cases $p=0$ ), ischemic heart disease ( 25 vs. $6 p=0)$, cerebrovascular disease ( 10 vs. $6 p=0.0027425069407323)$. Also, for these pathologies, different situations of association of two or more diseases in the same patient have been revealed.

Drug-related costs have also been analyzed according to pharmacological class consumption, concluding that antibiotics, anticoagulants and local topicals are predominantly used and therefore represent the bulk of drug costs.

The obvious difference was generated by both significant differences in pathologies and by the implementation of antibiotherapy and antibioprophylaxis protocols. The prevalence of hand traumas and benign or malignant tumors in the skin has oriented pharmacological therapies towards antibioprophylaxis without increasing infections associated with health care.

Medicines are the main measure in the fight against disease and recovery, consuming between 20 and $40 \%$ of the budget allocated to the healthcare system for developed countries [4]. Their use in a proper and responsible way contributes to saving lives and improving their quality, especially in the context of chronic diseases. At this moment, both in and out of hospital, drug use can be appreciated at a high level due to the emergence on the market of a multitude of generics, under various pharmaceutical forms that ease administration, with fluctuating continually growing prices, but also due to the increasing tendency in self-medication as a result of easy access to multiple sources of information [5]. Management of any case involves both the treatment of symptoms and comorbidities, including combating risk factors to prevent complications. Thus, there is an increased frequency of polypharmacy as a part of the defensive medicine [6,7], propelled by poor communication with the patient, which does not allow knowledge of its chronic treatment [8]. Therefore, administration errors and adverse events caused by drug interactions are favored [9], there are frequent changes to chronic therapeutical regimens, either because they are not available, or the clinician considers to be more effective other therapies traditionally used in the sanitary unit [10-12], with no clinical motivation at times [13]. All these aspects lead to an increasing consumption of drugs, but also to related costs, by increasing the number of days of hospitalization or the ones related to the sanitary materials used in the administration, as well as those necessary for the correct management of the hazardous wastes resulting from the respective activity [14]. In this context, medical protocols prove their usefulness as a control measure in increasing drug use, and this can be validated as a structural indicator in the process of assessing the effectiveness and effectiveness of protocols, of course under the conditions of effective communication between the patientand the medical team [15].

As shown in our study, the largest expense is recorded for antibiotics. Consumption of antibiotics is an important part of medical management, which requires attention both through their beneficial effects and by the possibility of the occurrence of microorganism resistance [16], butalso from an economic and financial point of view, being an intensively used pharmacological class, with estimated costs that increased from 10 to $15 \%$ in hospitals [17]. Whereas antibiotics were initially used with maximum efficacy, with therapeutic effect in a small amount, nowadays the risk of antibiotic resistance, the need for increasing amounts and the occurrence of new molecules impose the need to educate all those working in the medical field on prescribing and releasing antibiotics in order to develop consistent antibiotic administration policies [1820]. At the level of clinical departments, this is reflected in the use of antibiotic and antibiotic prophylaxis protocols, considered to be the best and cost-effective measure, with positive influences in terms of lowering costs and reducing the number of healthcare-associated infections generated by resistant germs. Also, the effectiveness of medical practice in both directions is also supported by the involvement of the pharmacist, the drug commissioner, the laboratory physician and the antibiotic use policy [21]. Clinicians should be kept informed about antibiotic stocks, about frequently use classes, consistent with the germ movement in that healthcare unit, and also of identified antibioresistants, all in an economic and financial context. These are all components of a strategy to optimize antibiotic therapy and to prevent the emergence of antibiotic resistance of microorganisms [22,23]. Also, in our study, there are highlighted favorable results obtained from the implementation of antibiotic and antibioprophylaxis protocols, aimed at reducing the consumption of antibiotics, the predominant orientation towards perioperative antibiotics and even the renunciation of antibiotics following a thorough and accurate assessment of the patient's status and infectious risk. In fact, mentions regarding the choice of the first-line antibiotic and the related scheme, as well as the indication of antibiotic prophylaxis depending on the operative moment are also present in the medical protocols for the various diseases

\begin{tabular}{|l|l|l|l|}
\hline \multicolumn{1}{|c|}{ Type of antibioprophylaxis } & $\begin{array}{c}\text { Number of patients 1st } \\
\text { trimester 2017 }\end{array}$ & $\begin{array}{l}\text { Number of patients 1st } \\
\text { trimester 2018 }\end{array}$ & $\mathrm{p}$ \\
\hline $\begin{array}{l}\text { Intraoperative Antibioprophylaxis } \\
-1 \text { dose }\end{array}$ & 49 & 93 & 0.000000000019508 \\
\hline $\begin{array}{l}\text { Antibioprophylaxis - 2 doses } \\
\text { administered every 12 hours }\end{array}$ & 3 & 12 & 0 \\
\hline $\begin{array}{l}\text { Antibioprophylaxis for more than } \\
\text { one day }\end{array}$ & 32 & 40 & 0.0052450126 \\
\hline
\end{tabular}

Table 2

SITUATION OF PATIENTS WHO RECEIVED

ANTIBIOTIC

PROPHYLAXIS 
treated in our service. Antibioprophylaxis was performed with Ampiplus $1.5 \mathrm{~g}$ (ampicillin - C16H18N3NaO4S and sulbactam - C8H10NNaO5S).

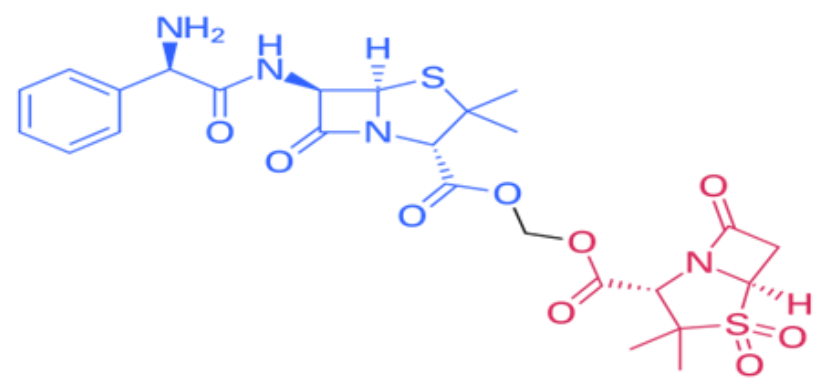

Fig. 5. Ampiplus chemical structure

The entire activity is completed by regular reports from the pharmacy, medical analysis laboratory and the pharmacovigilance commission, functional at the hospital level, and by the support provided by the antibiotic policy officer, respectively the infectious physician, in the prescription of restricted antibiotics. These aspects indicate the concern of the medical staff for the application of the best practices in the use of antibiotics in order to increase the quality of the services provided, guaranteeing the patient's safety, especially by minimizing the number of hospital infections, which have a strong impact on the patient's quality of life and are big consumers of resources, both individually and institutionally, and for the health system [24]. We can state that the situation is in line with that existing at the European level, as evidenced by the ARPAC study-Antibiotic Resistance Prevention and Control, based on data from 263 European hospitals. It was found that $86 \%$ of them had a drug commission, $84 \%$ had antibiotic prophylaxis and in $80 \%$ of them the antibioprophylaxis recommendation was found in the clinical guidelines corresponding to the pathology [25].

Studies in Romania showed that in hospitals that recorded increases in antibiotic costs of $63.7 \%$, after the implementation of the antibiotic prophylaxis protocols, the average consumption decreased by $14.9 \%$, the quantitative value of the injectable antibiotics decreased by $5.4 \%$, without detecting increases in the number of reported hospital infections [26].

The use of medical protocols significantly reduces professional variability, both in terms of integral case managementand pharmacological intervention, while also minimizing clinical risk. It also supports pharmacies in ensuring that drug stocks are kept in check, knowing very accurately the therapeutic needs. In order to maintain the effectiveness and efficiency of protocols, their periodic review should be considered, in line with specialized guidelines, drug market trends (the emergence of new drugs characterized by a very good cost-effectiveness ratio) and the economic and financial context of each healthcare unit, including the consumption history in relation to the obtained results.

\section{Conclusions}

Tracking drug use is an effective tool to increase the quality of medical services by avoiding polypharmacy, therapeutic errors and preventing the development of antibiotic resistance. All these aspects are supported by the implementation of medical protocols and, thus, drug use can be appreciated as a valid indicator of their effectiveness and efficiency.

\section{References}

1.ROGOZEA, L., et al. Rom J Morphol Embryol, 55.2, 2014, p. 719. 2.POPESCU, IG., SECHEL, G., LEASU, FG., TANTU, MM., COTOI, BV., ROGOZEA. LM., , Rom J Morphol Embryol, 59(3), 2018, in press 3.TANTU MM et al. Rom J Morphol Embryol, 55(3), 2014, p.803 4.WORLD HEALTH ORGANIZATION. Drug and therapeutic committees a practical guide. 2003

5.IANCU, M., BUCSA C., FARCAS, A., LEUCUTA, D., DINCU, A., MOGO'AN, C., DUMITRA'CU, D., BOJITA, M., Farmacia, Vol. 63, 1, 2015, p.80

6.GLINTBORG, B., ANDERSEN, SE., DALHOFF, K., Qual Saf Health Care, 16, 2007, p. 34

7.HOVSTADIUS, B., HOVSTADIUS, K., ASTRAND, B , PETERSSON, G., BMC Clin Pharmacol 2, 10, 2010, p.16.

8.FRYDENBERG, K.,BREKKE, M., Scandinavian J ournal of Primary Health Care, 30, 2012, p. 234

9.DE VRIES, EN., RAMRATTAN, MA., SMORENBURG, SM., GOUMA, DJ ., Qual Saf Health Care; 17, 2008, p.216

10.WILSON, S., RUSCOE, W., CHAPMAN, M., et al. J Qual Clin Pract, 21, 2001, p.104

11.LISBY, M., NIELSEN, LP., MAINZ, J., Int J Qual Health Care;17, 2015, p.15

12.BERGKVIST, A., MIDLOV, P., HOGLUND, P., LARSSON, L., BONDESSON, A., ERIKSSON, T., Eur J Clin Pharmacol , 65, 2009, p.1037

13.GALLINI, A., LEGAL, R., TABOULET, F., Br J Clin Pharmacol, 75:4, 2012, p.1142

14. OLIVEIRA FURUKAWA, P., KOWAL OLM CUNHA, IC., LUZ GONÇALVES PEDREIRA, M., BERYL MARCK, P., Acta Paul Enferm. 29(3), 2016, p.316

15.CONSTANTIN, DA., CIORICEANU, IH., TANTU, MM., POPA, D., BADAU, D., BURTEA, V., NEMET, GC., ROGOZEA, LM., Rom. J. Morphol. Embryol., 58, nr. 3, 2017, p.1121

16.FILIUS, PM., LIEM, TB., VAN DER LINDEN, PD., JANKNEGT, R., NATSCH, S, VULTO, AG., et al. J Antimicrob Chemother; 55(5), 2005, p. 805

17.HUDSON, S., Open University Press; 2004. p. 213

18.FALUP-PECURARIU, O., BLEO, L. et al. The Pediatric infectious disease journal, 30(1), 2011, p.76

19.LICKER, M., et al. Farmacia, 65.6, 2017, p. 929

20.MANU, P., ROGOZEA, L., American J ournal of Therapeutics, 23(2), 2016, p.326

21.*** ORD. 1101/2016 PRIVIND APROBAREA NORMELOR DE SUPRAVEGHERE, PREVENIRE SI LIMITARE A INFECTIILOR ASOCIATE ASISTENTEI MEDICALE ÎN UNITATILE SANITARE

22.LEE, .R., CHO, IH., JEONG, BC., LEE, SH., Int. J. Environ. Res. Public Health, 10(9), 2013, p. 4274

23.MAGIORAKOS, AP., SRINIVASAN, A., CAREY, RB., CARMELI, Y., FALAGAS, ME., GISKE, CG., Clin. Microbiol. Infect., 18, 2012, p. 268

24.VOICU, M., CRISTESCU, C. et al., Farmacia, Vol. 65, 2, 2017, p.225 25.BRUCE, J., MACKENZIE, F., COOKSON, B., MOLLISON, J., VAN DER MEER, JVM., Krcmery, V., Journal of Antimicrobial Chemotherapy, 64, 2009, p.853

26.DAINA, L., CARP, G., NEAMU, C., VENTER, A., ARMEAN, P., Farmacia, Vol. 63, 3, 2015, p. 407

Manuscript received: 24.10 .2018 